\title{
Microterritorializações e microterritorialidades urbanas
}

\section{Microterritorializaciones e microterritorialidades urbanas}

\section{Urban Microterritorializations and Microterritorialities}

\author{
Benhur Pinós da Costa \\ benpinos@gmail.com \\ Programa de Pós-graduação em Geografia - Universidade Federal de Santa Maria - UFSM
}

\begin{abstract}
Resumo: O texto explica os conceitos de microterritorialização e microterritorialidade, que representam as pequenas apropriações do espaço urbano na perspectiva cultural. Para isto se utiliza de estratégias didáticas de organização de princípios e subprincípios aos temas. Os princípios representam as explicações sobre forma e conteúdo relacionados aos conceitos em evidência. Para cada princípio explora mais dois subprincípios, para aprofundar no exercício da explicação.
\end{abstract}

Palavras chave: microterritorializações, microterritorialidades, território, forma, conteúdo, escala, homossexualidades.

Resumen:Eltextoexplicalosconceptos demicroterritorializacióny microterritorialidad, lo que representa pequeñas apropiaciones del espacio urbano en la perspectiva cultural. Para ello utiliza estrategias didácticas de organización de principios y subprincipios para los temas. Los principios representan la explicación de la forma y el contenido relacionados con los conceptos em evidencia. Para cada principio opera dos subprincipios más, para profundizar en el ejercicio de explicación.

Palabras clave: microterritorializaciones, microterritorialidades, territorio, forma, contenido, escala, homosexualidades.

Abstract: The text explains the concepts of microterritorializsation and microterritoriality, which represent the small appropriations of the urban space in the cultural perspective. For this, uses didactic strategies of organization of principles and sub-principles to the themes. The principles represent the explanations of form and content related to the concepts in evidence. For each principle explores two more subprinciples, deepening the exercise of explanation.

Key words: microterritorialisations, microterritorialities, territory, form, content, scale, homosexuality.

\section{INTRODUÇÃO}

O propósito deste artigo é sistematizar o pensamento a respeito das microterritorialidades e das microterritorializações. Representa uma abordagem teórica que se ocupa em definir estes dois conceitos com o objetivo de construção de uma discussão útil que possa 
servir como instrumento dedutivo para outras pesquisas que procuram entender as relações entre espaço social urbano e suas diversidades de apropriação relacionadas a reuniões de sujeitos identificados e se identificando com formas e práticas culturais singulares.

Entendemos que estes conceitos se referem a formas operacionais científicas que poderão ser utilizados por cientistas sociais, em especial geógrafos, para trabalharem as diferentes convivências estabelecidas na cidade contemporânea. Enfatizamos o compromisso do autor em tornar mais claras as complexas definições destes conceitos, em virtude da trajetória de um grupo de pesquisadores que atentam, por mais de uma década, as discussões sobre relações empíricas das realidades das diversidades culturais nas cidades e a análise geográfica, em especial territorial.

O texto está organizado em três momentos. O primeiro momento se refere a uma discussão sobre a posicionalidade do autor e os caminhos pessoais e profissionais que o levaram a entender a construção de microterritorialidades e microterritorializações nas cidades, em especial suas experiências de pesquisa - relacionadas com sua vida pessoal, na cidade de Porto Alegre - sobre as espacializações de convivências homoafetivas no espaço urbano. Este momento é importante para proporcionar um entendimento sobre o 'lugar' em que o autor está pensando e dialogando. Justificamos esta discussão devido à necessidade de esclarecer a individualidade da relação entre sujeito pensador, universo empírico e sistema teórico que convergiram ao processo científico. A discussão sobre a posicionalidade esclarece o contexto de produção de conhecimento e torna honestas as concepções aqui trazidas, podendo, assim, serem mais bem criticadas a partir de outras possibilidades de entendimento sobre $\mathrm{o}$ assunto.

O segundo e o terceiro momentos referem-se a uma estratégia didática construída para organizar o pensamento que definirá os conceitos em pauta. No segundo momento o texto tratará das microterritorializações, mais especificadamente, condicionando uma ideia de que há uma forma geográfica que constitui as diferentes reuniões e práticas culturais no espaço urbano. No terceiro momento, além da forma, que constitui o aspecto visível que pode ser localizado e espacializado, a partir de estratégias de representações geográficas, existe o conteúdo relacional destas reuniões, que implica partilhas de fazeres, apresentações e identificações entre sujeitos diferentes, além dos jogos relacionais estabelecidos. Implicam, também, conflitos e divergências diversas, que configuram certa instabilidade na construção das definições culturais das microterritorialidades.

\section{A POSICIONALIDADE: DE QUE 'LUGAR' ESTAMOS PENSANDO PARA ENTENDER MICROTERRITORIALIZAÇÕES E MICROTERRITORIALIDADES.}

Antes de tudo, propomos definir o 'eu' (do autor/escritor/pensador deste artigo) e dialogar sobre sua 'posicionalidade' (ROSE, 1997; MATURANA, 1997; KNOPP 2007; SILVA, 2009) no que se refere às ideias colocadas aqui. Acreditamos que este exercício é importante para esclarecer os caminhos teóricos e metodológicos que permeiam o desenvolvimento do pensamento sobre microterritorialidades e microterritorializações desenvolvidas neste 
ensaio. Esta necessidade é amplamente discutida em termos de processos científicos relacionados às geografias feministas na atualidade, porque todo estudo científico é um ato de recriação de uma realidade social, gerando consequências em relação a esta realidade e aos sujeitos ligados a ela. Esta postura exige uma leitura crítica sobre as posições teóricas exercidas no momento da escrita e o universo de referência do sujeito pensador sobre os sujeitos e espaços sociais estudados. Na máxima de Maturana (1997), o 'dito' vem de um observador, que observa, analisa e reflete sobre a realidade observada a partir de um complexo de posições subjetivas, que são seus aprendizados teóricos, seus acumulados empíricos e, inclusive, suas crenças e ideologias.

Pois bem, o tema das microterritorialidades e das microterritorializações nos é caro desde a graduação e desenvolvimento dos estudos de mestrado e doutorado, no Programa de Pós-graduação em Geografia da UFRGS, assim como sua relação com a realidade empírica da cidade de Porto Alegre, nos anos de 1990 e de 2000. Na energia da juventude procurávamos relacionar as experiências pessoais de diversão e de vivência da sexualidade com os caminhos intelectuais da Geografia. A proposição da pesquisa de mestrado intitulada A condição homossexual e emergência de territorializações (COSTA, 2002), reflete a vivência de um espaço social condicionada, sobretudo, às experiências homoeróticas, organizadas de forma fragmentada em porções diferenciadas do espaço urbano de Porto Alegre. O drama dessa realidade vivida se construiu a partir de uma dialética entre a dificuldade de assunção da homossexualidade, em espaços ora 'assexualizados', ora 'heteronormatizados' (relacionados a uma 'normalidade' das funções sociais hegemônicas) e a construção de 'linhas de fuga' (COSTA, 2002) ou possibilidades táticas e restritas de exercício das homoafetividades. Tratava-se de espaços restritos construídos por um mercado de diversão noturna underground (de estabelecimentos comerciais - boates e bares - que precisavam não ser tão visíveis na normalidade das funções e relações hegemônicas do mundo urbano) e partes do espaço público, ocupadas transgressivamente para encontros sexuais e amigáveis relacionados ao homoerotismo.

A cidade estava 'picotada' de pequenos espaços cujas diversidades de expressões culturais e sexuais particulares poderiam se desenvolver, contradizendo práticas institucionalizadas mais amplamente aceitas socialmente, que conduziam uma normalização de um espaço que precisava ser conquistado para uma sobrevivência futura. Tornava-se necessário assumir formas de apresentação de corpo e configurações de identidades não divergentes. Viviam-se duas realidades contraditórias: a necessidade de se estabelecer em um espaço cuja heterossexualidade é compulsória (BUTLER, 2010) e a realidade cujos desejos mais profundos poderiam ser alegremente exercidos em interação.

Aquele mundo hegemônico se tornava prepotente e chamava à realidade das coisas a fazer, estabelecendo assim uma condição à sua homossexualidade: uma necessidade de esconder-se e se restringir a espaços e tempos específicos de afetividade. O mundo se construía dialetizado por estes fragmentos e o grande desafio seria, então, fazer o possível para torná-los os mais próximos possíveis: isto representa o grande drama de grande parte das pessoas LGBTs (lésbicas, gays, bissexuais, travestis e transgêneros). A trajetória da construção da identidade de sujeitos LGBTs é especial neste desafio de tornar mundos 
não equivalentes em um conjunto de espaços de experiências mistas (certa desconstrução da heteronormatividade e possibilidade de homoerotizar o espaço e as relações sociais). É assim que as experiências pessoais se tornaram fontes profícuas das pesquisas relacionadas à Geografia, ciência que apresenta um discurso fortemente calcado na marginalização das mulheres e das diversidades sexuais (ROSE, 1993), porque suas construções de espaço referem-se à hegemonia do pensamento masculino e heterossexual. Não acreditamos que as construções teóricas sobre as territorializações homossexuais desestabilizaram este teor masculino e heterossexual da Geografia - tais estudos também se serviram dela. Por outro lado, todo aspecto deste trabalho se refere a uma Geografia subjetiva da tentativa pessoal de relacionar os fragmentos dicotômicos do vivido do espaço social, o que evidencia uma possibilidade de entender de outro viés este espaço.

Não havia opções teóricas ou elas estavam indisponíveis naquele contexto - seus limites e possibilidades. Ocorreu, assim, uma tática de se atrelar ao discurso científico existente disponível, no seu tempo e no seu espaço, remodelando seus próprios elementos no sentido de criar um 'entre-discurso' que pudesse se aproximar à realidade pessoal e empírica vivida. Havia muitos trabalhos sobre gênero e sexualidades na Geografia sendo desenvolvidos em outros contextos científicos no Brasil e em outras partes do mundo, mas podia-se notar que no período do final dos anos de 1990 eles mantinham certa dificuldade de se reunirem para a construção de um eixo epistêmico comum. Isto começará a ocorrer na metade dos anos 2000 até à atualidade. Nesse contexto, as possibilidades de encontro com novas epistemologias foram determinadas pela emergência de novas pesquisas sobre a diversidade cultural do espaço social relacionados à emergência da Geografia Cultural renovada (CLAVAL, 2001) no Brasil nos anos de 1990 e 2000, como a construção de espaços de discussão científica do NEPEC (Núcleo de Estudos sobre Espaço e Cultura, da UERJ, Rio de Janeiro) e do NEER (Núcleo de Estudos em Espaço e Representações).

A assunção da identidade de Geógrafo Cultural e/ ou Social foi crucial à sobrevivência destes estudos nesta época. No entanto, a vivência de um mundo de contradições e separações, regidas por formas de relações sociais hegemônicas e disputados por formas relações sociais subalternas, que lutam por reconhecimento, levou-nos à concentrar estudos na análise de territórios diversos que organizavam e desorganizavam o espaço social. Espaço este que, ao mesmo tempo em que estava homogeneizado por formas de relações que privilegiavam o masculino e a heterossexualidade, era disputado por diferentes formas de encontros e vivências das homossexualidades. As formas de disputas promovidas por identidades subalternas relacionavam-se com estratégias de reconhecimento que implicavam a necessidade de se localizar, de se apropriar de espaço e de se sentir protegido. Por outro lado, todos aqueles homossexuais que contribuíam para construção de espaços restritos de proteção para vivências de suas homoafetividades, também, de formas distintas, em relação ao referente identitário das homossexualidades, aprendiam e competiam por uma inserção no espaço do lazer, do trabalho, da educação formal, do consumo e da família regidos pela misoginia e heterossexualidade compulsórias.

Os referentes das separações vividas se estabeleciam por um jogo de diferentes formas de assunção e não assunção da identidade homossexual (sair e não sair do 'armário' - ver 
a discussão sobre epistemologias do 'armário' em Sedgwick, 2007). Assim, ser homossexual se relacionava a uma condição de identidade social subalterna e as possibilidades de vivências das homoafetidades necessitariam, então, a construção (emergência) de espaços apropriados, chamado de 'territorializações', assim como táticas muito sutis de transgressão de espaço cujas relações sociais eram heteronormalizadas. A relação do sufixo 'ção' foi uma estratégia conceitual estritamente relacionada ao universo empírico experiencial: não poderiam ser territórios, pois os espaços apropriados pelas homossexualidades não eram fixos, eram mutantes e cambiantes e facilmente permeáveis - apontavam somente a possibilidade da reunião de corpos e um conjunto de trocas e jogos de interação.

$\mathrm{Na}$ continuidade dos estudos (tese de doutoramento) decidimos colocar o prefixo 'micro' nas territorializações para enfatizar a questão escalar. Nossos conceitos se apoiam fortemente em experiências pessoais como homem gay e geógrafo cultural, mas, remetem também a um esforço imenso de se colocar fora deste universo. Neste sentido, além da referida posicionalidade e a assunção deste aspecto, cremos que exista também uma forma dialética que todo pesquisador deve enfrentar em sua vida acadêmica: uma eterna reflexão entre o que 'dele' influencia seus estudos e cria/recria a realidade pesquisada, e um eterno esforço de se separar e menos influenciar a realidade. Talvez este fosse nosso esforço e preocupação na tese de doutorado: procurar explorar o mundo de outros sujeitos sobre os espaços de convivência homoerótica de Porto Alegre, fato que nos aproximou da fenomenologia. Sobre isto, para ressaltar a condição de posicionalidade de nossas pesquisas, reproduziremos a fala em primeira pessoa durante apresentação no IV Seminário sobre Microterritorialidades nas Cidades e IV Seminário sobre Múltiplas Territorialidades:

Posso dizer que minha posicionalidade se refere a tudo que sei sobre minhas vivências das homossexualidades e as vivências de meus pesquisados-colaboradores. Os resultados que representam discussões teóricas e empíricas do debate sobre microterritorialidades e microterritorializações são um encontro entre a reflexão sobre minhas vivências intimas nos espaços que convivo (aos quais me incluo e outros nos quais perco percepção de identidade) e a reflexão estabelecidas por meus pesquisados-colaboradores, das quais, ainda, são contradições entre minhas interpretações dos fatos narrados por eles e as próprias narrações que se referem ao que eles realmente queriam dizer.

É neste sentido que entendemos os resultados de um trabalho científico como a construção discursiva de um encontro entre pesquisador e pesquisado. Certamente a preponderância revela-se no discurso do próprio pesquisador, que detém o poder de interpretar, e os veículos de publicação científica. Mas deve haver um esforço de se afastar da complexidade de suas próprias concepções e seu poder de controlar a realidade dos fatos. Em nossa trajetória construímos o entendimento de homossexualidades como um conjunto de experiências sexuais relacionadas ao mesmo sexo muito diversas, nas quais também são diversas as experiências conduzidas por cada sujeito em microterritorializações adjetivadas como das homossexualidades.

Há algo de singular em cada vivência dos espaços de diversão e busca sexual gay para cada sujeito que as vive. Isto nos permite, como homem gay, pesquisar as sociabilidades e 
territorialidades gays, uma vez que ocorrem também diversas contradições referentes às nossas próprias concepções identitárias referentes às homossexualidades. Para um pesquisador que apresenta uma posicionalidade de homem gay existirá sempre um conjunto de estranhamentos e outro de identificações que permitirão a reflexão sobre os acontecimentos e expressões nos espaços de convivência gay. O esforço é concentrar-se na realidade das situações narradas pelos colaboradores e na minúcia das materializações das ações dos corpos em interação. Os registros (de diferentes formas) exaustivos, assim, tornam-se sempre parte deste esforço de afastamento.

Para construção destes conceitos, a partir destes parâmetros empíricos, nos posicionamos junto a fortes construções teóricas vinculadas à Geografia Cultural, aos estudos do cotidiano (principalmente à etnometodologia e ao interacionismo simbólico) e à fenomenologia. Como estratégia de sistematização didática, utilizaremos os conceitos de 'forma' e 'conteúdo' desenvolvido pelo geógrafo Milton Santos (1996). Estes conceitos serão entendidos aqui como princípios, que não se apresentam somente como uma estratégia didática, mas se realizam na compreensão de que as microterritorialidades e as microterritorializações referem-se à construção de uma 'forma'. Esta é o encontro de corpos relacionados a uma reunião e interação social (no caso uma reunião de sujeitos homossexuais e as estéticas produzidas em virtude de algum elemento da complexidade de uma cultura gay), que se torna visível (semivisível, muitas vezes) socialmente, e também de um 'conteúdo', que representa a profundidade interpretativa dada pelos sujeitos que se colocam no contexto de agregação e interação entre corpos, assim como pelo pesquisador que se propõe interpretá-lo. O conteúdo se torna o desafio primordial da construção do conhecimento sobre as relações socioculturais que constroem o espaço interacional específico e configuram a apropriação dele (estabelecendo o teor territorial).

\section{PRINCÍPIO PRIMEIRO: FORMA (AS MICROTERRITORIALIZAÇÕES)}

Entendemos como 'forma' a construção material das microterritorializações, o que evidencia a reunião de corpos e a partilha de elementos estéticos construídos individual e coletivamente. A 'forma' está além da reunião dos corpos na intrínseca relação com o espaço construído. Existem duas variáveis importantes para o entendimento da forma como microterritorialização: a primeira é o entendimento do espaço social como anterior a microterritorialização, isto é, o espaço como ente primeiro e o território como apropriação deste espaço, na proposta de pensamento desenvolvida por Raffestin (1993). A segunda variável remete ao aspecto formista (MAFFESOLI, 2002) que estabelece a partilha estética coletiva e a reunião localizada no tempo e no espaço.

Para a segunda variável, entendemos que o espaço social permite diferentes formas de apropriação informal além dos propósitos de configuração formal relativa às interações sociais condicionadas a formas sociais hegemônicas e funcionais (relações e práticas sociais hegemônicas que regram a afetividade, o trabalho e o consumo). O espaço social como construção moderna que se destinou ao regramento dos comportamentos e das relações 
sociais se produziu como incompleto, hesitante e contraditório (SANTOS, 1996; TOURAINE, 1994). Incompleto porque não abarca todo ecúmeno; hesitante e contraditório porque a construção de desigualdades (econômicas) sociais e formas subalternas de identidade (culturais) são importantes para a afirmação dos modelos e polos hegemônicos de poder. As contradições e desigualdades são situações sociais contidas nos próprios processos hegemônicos da modernidade (TOURAINE, 1994), assim como as identidades ditas desviantes são pressupostos de nomeação e definição de corpos e comportamentos que asseguram a manutenção daquilo que se produz como normal e hegemônico (FOUCAULT, 1988).

Assim, são condições da própria normalização das relações, das atividades e dos comportamentos no espaço social os processos de construção de transgressões destes elementos e produção de corpos, condições individuais e coletivas divergentes das primeiras. O espaço social primeiro, na qual suas formas são condicionadas a um planejamento vertical e tecnocrático, imerso em padrões ideologizados condizentes as instituições sociais hegemônicas burguesas e aos propósitos de reprodução do capital, é constantemente transgredido por processos socioculturais e identitários divergentes, mas que não se isentam ou se separam totalmente da produção hegemônica primeira. As microterritorializações, então, são formas materiais da reunião de corpos e práticas subalternas (divergentes, mas nem tanto...) produzidas a partir de um espaço social primeiro (que se pretendia organizado, homogêneo e ordenado). São condições de apropriação do espaço público além do caráter nomista desenvolvido por Gomes (2002), na perspectiva da construção de espaços de identidade, que o mesmo autor denomina de genoespaço; ou, então, vínculos de localizações materiais (estabelecimentos e arquitetônicos) produzidos por um mercado que explora justamente as contradições da ordem social, ou um mercado de partilhamento de identidades e formas culturais pós-modernas (JAMESON, 1991).

A outra variável se constrói em virtude de um processo social contemporâneo relativo a uma intensa aura social relacionada à partilha de gostos estéticos, ou o formismo de Maffesoli (2002). Para o autor, as condições sociais da atualidade são produzidas pela necessidade de partilhas de gostos, assuntos e apresentações de corpo e isto estrutura o conjunto de experiências individuais e coletivas. O social, assim, se constrói pelas ações não lógicas e pela socialidade, ou seja, pela empatia, por uma solidariedade orgânica e pela partilha de experiências comuns e banais. $\mathrm{O}$ espaço social antes visto como produto de ordens hegemônicas que procuram homogeneizá-lo e normatizá-lo é fruto, na verdade, de um sentimento de 'proxemia' ou de 'microlocalismos' geradores de cultura, de memória e de sensibilidade estética. Existe, assim, uma valorização de um modo de aparecer e isto produz diferentes formas de se relacionar e de se reunir condicionadas por uma experiência sensível, mas que guarda, em si, profundezas sobre seus elementos explicativos (além das aparências). O imperativo se produz no presente e no local. Estas relações presentes e localizadas apresentam conexões em outras escalas, mas tudo se refaz e se reconstrói na forma 'aqui' e 'agora' (se reproduzem estéticas e formas culturais globais, mas elas se relativizam, se reconstroem e se transformam na experiência sensível coletiva).

As microterritorializações regidas pelo princípio de forma contém esta dialética das desigualdades e das contradições produzidas pelos próprios processos sociais, produzidas 
em partes do espaço social urbano cujos regramentos são mais frouxos ou cuja força da transgressão permite e evidencia o conflito entre ordem e desordem. Assim como um sintoma de produção sensível dos corpos e das relações (ocorre, muitas vezes, também a transformação da materialidade abrangente) definidas pela criatividade sensível do presente e do local partilhado coletivamente. Há um conjunto de processos dialéticos neste contexto: a dialética entre formas estéticas globais e a produção e reinvenção de formas estéticas locais (presentismo); a dialética entre produção hegemônica do espaço moderno (condição do espaço social primeiro) e a microterritorialização como apropriação de transgressão (embora também parte importante das manutenções de condições hegemônicas normativas - a diferença desviante permite também o reforço dos polos normativos). A 'forma' ou microterritorialização contém estas contradições todas: transgride (contra hegemonias produzidas pelos subalternos) e afirma (o desvio permite o reforço da norma); conduz uma criatividade sensível do 'aqui-e-agora' coletivo e identitário (produz novas ações e representações), assim como está condicionada a um movimento cultural global (como estratégia de mercado cultural global e/ ou como veículos de contraculturas dissidentes que conseguem, por vias das redes de comunicação, se globalizar).

A 'forma' é a condição mais fácil de observar: é o que se coloca aos olhos, ou a interação 'aqui e agora' (no espaço e no presente), que nos coloca frente a um conjunto de situações inusitadas e incompreensíveis. No paradigma estético de Maffesoli (2002), esta situação inusitada colocada aos sujeitos comuns mobiliza um gosto estético e uma sensibilidade de partilha de admirações que não é lógico: estão contidas nas experiências das psiques individuais condicionadas as memórias adquiridas no presente e no espaço 'comunitário'. Esta memória sensível é admirada pelo sujeito que se coloca na forma e esta (partilha coletiva e experiência sensível) produz as condições do corpo do sujeito (traços físicos e formas de se apresentar, de pensar e de avaliar a si mesmo e aos outros). A 'forma' apresenta-se microterritorialização num espaço partilhado muito pequeno e refere-se a um processo de apropriação informal, pouco duradoura, instável, flutuante e periódico (por isto o sufixo ' 'ção' - construção de um processo de apropriação ou território).

A partir da 'forma' que obtemos os registros de imagem e estabelecemos as pistas para organizar os trabalhos de campo. O pesquisador deve, assim, se deparar com o inusitado, assim como o sujeito comum se depara. Pensamos que a empatia é importante para o sucesso de entendimento daquilo que não é lógico: as formas sensíveis. Assim como aquele sujeito que se emociona em encontrar e partilhar determinada reunião microterritorializada, também o pesquisador deverá apresentar esta emoção. Em termos metodológicos deverá acontecer a empatia, mas, ao mesmo tempo, o distanciamento. Esta é outra dialética da microterritorialização: a presença e a empatia (que torna o pesquisador os próprios sujeitos da microterritorialização) e a construção de um 'lembrete' que deverá sempre o trazer de volta ao distanciamento de pesquisador. O 'lembrete' poderá ser a partilha das experiências pessoais entre pessoas não microterritorializadas e, de preferência, vinculados ao mundo acadêmico-científico. A troca de impressões na busca de um trabalho coletivo é necessária neste tipo de empreitada, para proporcionar o pensamento além da solidão intelectual e racionalizar sobre aquilo que se sente na microterritorialização. 
A microterritorialização remete a construção de uma micropaisagem que revela o encontro de um conjunto de corpos em um grupo ou agregado social (COSTA, 2002; PEDROSO, 2007). Não podemos exatamente entender grupo social em virtude da condição formista da microterritorialização (instabilidade, periodicidade flutuante, flexibilidade, formas não lógicas de ação, senso estético). Melhor entender como agregado social, que revela melhor este caráter instável e mutante. Além disto, existem diferentes formas de densidade da microterritorialização: algo muito visível pelo 'apinhamento' e formatação de um número razoável de sujeitos em interação; ou algo quase imperceptível ou 'camuflado' entre outras materialidades da cidade. O contraste aqui se evidencia pela: construção de uma identidade forte de sujeitos que se propõem estarem visíveis como celebração de uma diferença que não poderá ser vivenciada em outros espaços sociais; ou contido nas vivências 'subterrâneas' que transgridem os espaços previamente construídos para determinadas funcionalidades - assim como contido no imaginário partilhado coletivamente em interações específicas de uma cultura urbana ou condição identitária marginal que preza pela invisibilidade (os assuntos circulam nas interações sociais inusitadas e informam sobre localidades nas quais determinadas ações e relações poderão ser estabelecidas).

Em relação às microterritorializações das homossexualidades, elas ocorrem em diferentes formas e estratégias de mercado de diversão noturna: desde os estabelecimentos como bares e boates gays, que se localizam em lugares 'escondidos' no espaço urbano, permitindo a discrição na chegada dos frequentadores e assumindo uma condição típica de gueto gay (alguns estabelecimentos para sexo entre homens, como saunas gays, vídeo locadoras e cinemas pornôs, organizam uma fachada cujos atributos estéticos não visibilizam o tipo de negócio estabelecido ou mudam os aspectos da frequência, como os cinemas muito frequentados por homossexuais, mas cuja fachada mostra que se destina ao público heterossexual); assim como as festas e bares gayfriendly que assumem uma identidade mista dos frequentadores e prezam pelo empoderamento e visibilidade da diversidade. As condições de atratividade dependem do contexto de vida do sujeito LGBT (em relação à assunção - ou não - da identidade sexual, assim como suas predisposições de experiência estéticas momentâneas). As diversidades de experiências microterritoriais disponíveis revelam-se compatíveis com uma experiência estética, de afetividade e desejo, assim como a sensação de partilha de imagens e sons específicos (formas de apresentação dos corpos, decoração da casa, músicas que pretendem ouvir, formas de relações estabelecidas). Relações não lógicas e sensíveis se tecem, mas elas são aparências que guardam as profundezas das predisposições psíquicas e cognitivas dos sujeitos em interação.

O mercado LGBT se desenvolveu muito e permite uma diversidade de experiências identitárias e sensíveis referentes às homossexualidades. A cidade de São Paulo, por exemplo, permite uma diversidade de casas de frequência LGBTs que diferem muito em relação às sensações, relações e apresentação dos corpos que abrigam, assim como a capacidade de consumo de seus frequentadores. Em relação ao espaço público, existem diferentes níveis de visibilidade e invisibilidade, desde cantos de praças e parques cujos encontros sexuais são velados, perpassando banheiros públicos cuja sutileza das formas de contato são importantes, até a apropriação e o denso apinhamento coletivo de lugares públicos 
destinados à proteção e visibilidade das práticas afetivo-sexuais das homossexualidades, como o Parque da Redenção nos domingos à tarde (Porto Alegre), a localidade do posto $9 \mathrm{e}$ Farme de Almoedo em Ipanema (Rio de Janeiro), o bar do Deca na Praia Mole (Florianópolis). As sutilezas dos encontros homoeróticos são informações que circulam entre a população LGBT, informando sobre partes do espaço público nas quais encontros podem acontecer, assim como festas destinadas a públicos bem específicos nas quais sensações singulares poderão ser vivenciadas. O trabalho de Parker (2002), por exemplo, aponta certas linhas e horários de trem na cidade do Rio de Janeiro onde contatos homoeróticos poderiam ser estabelecidos entre os frequentadores. Inúmeras táticas espaciais são estabelecidas e elas prezam a vivência constante do espaço urbano em virtude dos desejos homoeróticos. Parker (2002) nos fala de uma 'homoerotização' do espaço urbano como produto destas diferentes táticas. Importante que as localizações e a tempo das ocorrências são partilhados como formas de informação e conhecimento, o que determina as microterritorializações.

\section{SEGUNDO PRINCÍPIO: CONTEÚDO (AS MICROTERRITORIALIDADES)}

Além daquilo que está posto na realidade dos corpos em reunião em uma apropriação coletiva de partes do espaço urbano - que é entendido como uma 'forma' em formação, visível por alguns atributos estéticos partilhados - há o conteúdo, que se refere às próprias condições compartilhadas - como atributos e atribuídas pelos sujeitos em interação, na construção de uma 'regionalidade - cultural - do cotidiano' (GOFFMAN, 1996), delimitado no espaço restrito e no tempo dos acontecimentos presentes. Goffman (1996) apresenta a ideia das 'regiões do cotidiano', nos quais os sujeitos interagem a partir de perspectivas de representações a que estão envolvidos. Para o autor, o cotidiano é multiplicado de regiões cujos sujeitos conduzem suas atividades, suas formas de comunicação e de apresentação a partir da partilha de representações. As representações, neste sentido, são sensos práticos nos quais os sujeitos adotam linguagens e formas de saber-fazer comuns (TEDESCO, 2003), tornando o sujeito capaz de descrever, perceber e interagir segundo categorias formais que se tornam cotidianas e normais para os membros. Além da noção de práticas, existem as noções de 'reflexibilidade', account, 'membro' e 'regra' (COULON, 1995; TEDESCO, 2003), definidos na etnometodologia.

Reflexibilidade é a capacidade de o sujeito partilhar espécies de códigos internos, como uma linguagem interna do vivido que estrutura as ações e as situações. O sujeito não reflete na interação 'aqui e agora', mas se identifica e apreende um conjunto de códigos que possibilitam a interação. Ele partilha representações a partir da comunicação e repete ou imita atos apreendidos na memória como sendo ações próprias suas. Account define os acontecimentos normais do cotidiano, a tipicidade de probabilidades de ocorrência, como situações as quais os sujeitos sabem que ocorreram no passado e poderão acontecer no presente e futuro, como um conjunto de conhecimentos guias para construção de suas ações em determinadas situações. O membro é dotado do savoir-faire, como um corpo situado dotado capaz de construir dispositivos de adaptação e métodos e modos de agir nas 
situações partilhadas. Finalmente, as regras "manifestam-se na capacidade do indivíduo em identificar as ações necessárias em determinadas circunstância e promover o estado normal das coisas" (TEDESCO, 2003, p. 104). As regras articulam-se de forma 'indexical' (COULON, 1995) e são atreladas à capacidade de 'reflexibilidade' do sujeito, articulando intenções e justificações partilhadas por todos os membros: define os fatos/acontecimentos normais do cotidiano; dão seu caráter típico e sua probabilidade de ocorrência, as formas de comparação com fatos passados e os acontecimentos futuros; também atribui um significado causal as ações operadas pelo ator; pela qual são julgados os fatos necessários à ordem natural ou moral de um ator ou de uma sociedade.

Os próprios corpos em interação poderão ser entendidos como conteúdo, se analisarmos que eles 'preenchem' e se apropriam de um espaço (arquitetônico ou parte do espaço público). No entanto, queremos deixar claro que o sentido das microterritorializações como forma (ou 'forma em formação' na ideia do formismo) é a própria reunião dos corpos e que a ideia de conteúdo é esta necessidade de adentrar as profundezas dos motivos, representações, regras e identificações da reflexibilidade compartilhada. Antes deste pensamento, o próprio espaço poderia ser a forma (como construção material social antecedente - o urbanismo de uma praça, parque ou rua e a arquitetura de uma boate ou bar, condicionados a um conjunto de ideias que se materializam a partir da homogeneidade planejadora do social) e os corpos o conteúdo que preenchem estas formas. No entanto, as microterritorializações são uma segunda instância do espaço social, ou seja, (micro) território (ação) que contradiz o processo espacial primeiro, o reinventando e produzindo outra condição de espaço (por isto território, porque se apropria do espaço primeiro por outra lógica espacial).

Assim as condições de forma e conteúdo se alteram: a forma será então os próprios corpos em reunião e o conteúdo o 'fundo das aparências' (MAFFESOLI, 2002) como os sentidos da apresentação e da relação deles. É como se quiséssemos limpar o nível da homogeneidade e privilegiar a heterogeneidade do espaço social, tornando cada microterritorialização uma condição geográfica nova (visto pelo viés territorial) ou uma reinvenção sobre as formas e conteúdos primeiros. Assim teremos que entender as próprias reuniões dos corpos como as formas espaciais e as relações e jogos de objetividades e subjetividades como conteúdos espaciais. Isto implica entender as relações sociais como o próprio espaço, na perspectiva de Doreen Massey (2009), que constrói e reconstrói constantemente o espaço, como um conjunto de 'estórias até agora' (corpos em relações 'aqui e agora') que o reconstituem constantemente, produzindo outro.

A ideia de separar o princípio de conteúdo articulando com o conceito de microterritorialidades (diferente - mas nunca separado, sim articulado, imbricado - de microterritorialização) apresenta-se como uma questão didático-sistemática que leva à complexidade de compreensão dos propósitos desta discussão. Se pensarmos nas profundezas da reunião territorializada de corpos a partir das relações estabelecidas, teremos que evidenciar dois níveis de análise: o primeiro nível refere-se ao coletivo (os processos que cimentam as relações - as questões socioculturais) e o segundo nível refere-se ao individual-subjetivo. No nível coletivo existirá a necessidade de se pensar as escalas (além 
da própria microterritorialização, as informações, signos e valores culturais trazidas de outras escalas, principalmente em tempos de circulação global e facilitada da informação), como as construções próprias das relações estabelecidas no 'aqui e agora' que reinventam condições produzidas em outras esferas e escalas sociais. No nível individual acontecerá a dialética entre a reflexibilidade compartilhada, como construções coletivas de representações que conduzem o savoir-faire dos membros, e as subjetividades contraditórias destes próprios, que trazem perturbações na manutenção das práticas culturais estabelecidas (acreditamos que sempre há um processo individualizado de avaliação do sujeito sobre os aspectos de si e dos outros que compartilham relações, gerando conflitos de existências vivenciadas entre o agregado microterritorial, o que perturba a própria construção das relações espaciais, gerando transformações e trânsito de participantes).

Dessa forma, além da objetividade da própria reunião (visibilidade da materialidade da reunião e relação dos corpos), há a objetividade do 'cimento acional', ou a ação e interação entre sujeitos em reunião, que produz e é produzida pela forma em formação (a reunião ou o agregado social). A objetividade são os 'micro-rituais' e projeções míticas partilhadas que ligam os sujeitos diferenciados em um 'estar-junto' (MAFFESOLI, 2002). Os 'micro-rituais' são ações coletivas relativamente organizadas (não rituais formais e mais rígidos, como os religiosos, por exemplo) e as projeções míticas se apresentam pelas imagens de ídolos e pelas histórias que transitam como 'fantasmas' (SILVA, 2001) das quais quase ninguém as vivenciou, mas todos acreditam que fez parte de uma realidade admirável. As microterritorialidades das homossexualidades trazem consigo o compartilhamento de estórias das aventuras sexuais e de situações de empoderamento (muitas delas relacionada a atos 'fechativos' - escandalosos que contradizem a rigidez dos comportamentos misóginos, da regra de adequação do corpo ao gênero e dos tabus de se tratar a sexualidade somente espaço privado) de ícones LGBTs locais.

Em Porto Alegre, por exemplo, existem muitas estórias partilhadas por uma comunidade LGBT imaginada. Dizemos imaginada porque são informadas entre membros que não se conhecem e estão fora das próprias microterritorializações e das relações 'aqui e agora' - ou perpassam os assuntos presentes nas diversidades destas -, ligando diferentes sujeitos em diferentes situações, como fantasmas que sobrevoam uma determinada população (as identificando e as unindo em distância espacial e temporal). Muitos destes fatos contatos e sabidos coletivamente produzem ícones LGBTs: como as estórias da Nega Lu e outras travestis e drag queens locais e suas aparições extravagantes no passado do bairro Bom Fim, Parque da Redenção, Centro e Cidade Baixa.

Os 'microrrituais' cimentam também um 'estar-junto' de microterritorialidade, principalmente as apresentações e comportamentos corporais, muito deles envolvidos com expressões que se repetem com objetivo de maleabilizar as performances de gênero (transgredindo-as), muito observado nas imitações gestuais que ocorrem nas pistas de dança em boates e bares LGBTs, além de também expressões em agrupamentos fortes e visíveis de LGBTs em espaço público (vide os exemplos do Parque da Redenção, da Praia de Ipanema e da Praia Mole). Atualmente podemos acessar inúmeros vídeos de boates LGBTs em São Paulo, nas quais podemos perceber certas formas de expressão de corpos 
na dança e nas apresentações artísticas que se repetem em cada encontro em cada boate. Estes micros-rituais cimentam a reunião dos corpos e produzem as microterritorialidades.

Quando percebemos esta objetividade de apresentações, condicionamos isto à condição de microterritorialização (os corpos e a objetividade de suas formas e apresentações estéticas). Porém existem condições simbólicas partilhadas e códigos reconhecidos (ou não reconhecidos por alguns, estabelecendo alguns conflitos internos) que se apresentam como questões de identidade e de cultura estabelecidas individual e coletivamente. Além da descrição da forma (microterritorialização), há a necessidade de reconstrução discursiva dos elementos simbólicos, das projeções subjetivas e dos sentimentos individuais sensibilizados coletivamente. A objetividade do conteúdo (microterritorialidade) é algo que poderá ser construído discursivamente pela tentativa do pesquisador se introduzir, participar e tornar sensível para si mesmo a emoção dos próprios sujeitos em sociabilidade. Há de se entender por meio de uma 'reflexibilidade-refletida' (se apoderar do savoir-faire, mas também ter a capacidade de refletir sobre ele, em termos de objetivos de resultados de pesquisa - construção do 'lembrete') as formas de entendimento mútuo sobre os elementos que unem os sujeitos e os significados dos ritos e mitos partilhados.

No entanto, há outro problema. Além das objetividades das reuniões, dos 'micro-rituais', que posicionam e estabelecem as posturas dos corpos e a objetividade dos assuntos verbalizados, há uma subjetividade inerente a cada um dos sujeitos participantes. Isto representa algo que, ao mesmo tempo, estabiliza a reunião (pela pré-disposição íntima dos sujeitos que participam), como também a desestabiliza pelas incapacidades ou falta de interesse íntimo em partilhar elementos objetivos da microterritorialidade. Por este sentido podemos pensar que as microterritorializações são conduzidas por 'microterritorialidades paradoxais', trazendo para o debate a discussão de "espaço paradoxal" de Rose (1993), também trabalhadas por Silva e Ornat (2012). Além de ser um campo de sentimentos compartilhados e de condições intimas de identificações com a coletividade microterritorializada, os elementos simbólicos construídos por uma aura sentimental coletiva empodera diferenciadamente sujeitos microterritorializados. Existirão aqueles mais engajados nos propósitos da reunião e eles condicionam a apropriação espacial fazendo que outros os sigam. No entanto, estes outros apresentam diferentes intimidades avaliativas dos acontecimentos, ligando-se e exercendo diferenciadamente os rituais, relações, comportamentos e apresentações estéticas partilhadas. Existirão aqueles localizados mais perifericamente, cujas suas intimidades e avaliações subjetivas (por diferentes motivos relacionados à psique), assim como suas incapacidades de seguir aqueles admirados, tornam eles semi-presentes, quase ausentes, muito mais como expectadores do que habituées.

Estas contradições evidenciam a permeabilidade da microterritorialização (aqui falamos da forma constituinte) em conter sujeitos não tão atentos aos acontecimentos e jogos de imitação, menos 'nativo' e mais 'turista'. Neste sentido, poderá haver contradições inerentes aos comportamentos microterritorializados: a diferença periférica poderá exercer um fascínio e uma vontade de agregação para certos sujeitos (os sujeitos centrais em relação aos periféricos); para outros poderá ocorrer sentimentos de estranhamento e sensação de invasão do espaço próprio. Estes elementos denotam as condições de microterritorialidades 
mutantes das próprias microterritorializações, cujas suas permeabilidades trazem consigo uma constante disputa de centros simbólicos de identificação e margens (incapazes de acompanhar os propósitos que se pretendem homogêneos). Este contado com diferenças dialeticamente reunidas em prol de uma igualdade (formas estéticas diferenciadas, mas que convergem ao desejo homoerótico específico, por exemplo) torna as sensações evasivas e conduzem a constantes mutações a cada situação que se microterritorializa, podendo tornar exaurido os reais motivos da realidade da reunião (extinguindo-a). Isto faz com que os mesmos sujeitos procurem novas situações de sensações coletivas microterritorializadas.

\section{SUBPRINCÍPIOS DE FORMA E DE CONTEÚDO}

Para aprofundamento das discussões sobre microterritorialidades e microterritorializações, trataremos subprincípios para as noções de forma e de conteúdo, procurando esclarecer ainda mais o teor teórico destes conceitos. Serão dois subprincípios para forma e mais dois para conteúdo. Estes subprincípios estarão mais relacionados às evidências empíricas das pesquisas as quais o pesquisador se detém: as apropriações espaciais referentes às reuniões de sujeitos LGBTs.

\section{a. Primeiro subprincípio de forma: o território primeiro e a sobreposição da territorialização.}

Quando observamos microterritorializações LGBTs em espaço público, há antes um espaço construído e uma função a ser exercida (ações, construções e realizações de uma estrutura planejadora hegemônica do espaço social) e uma apropriação (indevida) de uma ação e relação (também indevida). As microterritorializações são como transgressões do espaço primeiro. Este espaço, por certo viés, também poderá ser entendido como território primeiro, uma vez que se constrói pela objetividade e materialização de ações e realizações de um poder planejador sobre o espaço, produzido a partir de posições ideológicas que pretendem uma ordem formal, fundamentando as práticas comuns do cotidiano.

As microterritorializações se constituem, neste caso, como uma ocupação de um 'pedaço' de uma praça, de um posto de gasolina, de um banheiro público, de espaços de um determinado shopping center ou de um local no supermercado ou de uma loja, de uma feira livre, etc. A microterritorialização, então, pressupõe a transgressão de uma configuração do espaço social preexistente (território primeiro como ente de construções e relações produzidas por ações de uma ordem social vertical). Sendo assim, produz um conflito entre o uso recorrente que pressupõe a funcionalidade do espaço primeiro, mas, também, se constrói entre lugares cujas ordens e normalizações das práticas são escassas (lugares pouco frequentados em determinados dias e horários, por exemplo). Muitas vezes, a apropriação se dá pelo esvaziamento do uso do espaço (em períodos em que cessa a circulação com objetivos funcionais), indicando que o poder que o rege e controla 
(coerente com a materialidade, no qual as práticas sociais se normalizam e marginalizam seus desvios) se apresenta mais frouxo.

O trabalho de Silva (2013) exemplifica muito bem este processo em terrenos baldios onde seu desuso, pelo mercado e pelas ações privadas sobre o espaço, permitiu a formação de pequenas áreas frequentadas para a prática homossexual. Isto é bastante comum em diferentes cidades de diferentes tamanhos no Brasil (COSTA, 2014). As praças e parques urbanos são lugares de ocupação de população marginal e subalterna em determinados horários de esvaziamento durante o dia (dias chuvosos e perto do meio dia) e, principalmente, durante a noite. O Parque Farroupilha (popularmente conhecido como Parque da Redenção), em Porto Alegre, faz parte do imaginário da população LGBT da cidade, nas quais histórias de repressão, de empoderamento e de diversão se misturam. É neste lugar que os grandes eventos LGBTs se realizam, mas também é sempre alvo de discursos que procuram o normatizá-lo em virtude das práticas estabelecidas ali (atualmente existe um debate sobre a necessidade de cercar o parque e regrar as convivências).

Ocorre aqui uma observação importante: os sujeitos e as práticas e os usos indevidos são produzidos como formas coletivas de identidades estigmatizadas que, contraditoriamente, são produzidas pela própria sociedade e urbanidade como desvios/margens/exclusões/anormalidades/criminalidades, que reforçam elementos simbólicos dos próprios padrões em uma função simbólica de polarização e diferença (geralmente organizadas como polos binários sobre norma e desvio). Dessa forma, paradoxalmente, representam formas e conteúdos de reuniões cuja sociedade 'deixa espaço' e, periodicamente, pratica algum ato repressivo como demonstração de poder e produção visível de disciplina. Por este viés, ocorrem possibilidades abertas à transgressão que representam incapacidades ou estratégias das hegemonias abarcarem todo ecúmeno, como exemplos que serão reprimidos para não serem seguidos. Esta relação entre reconhecimento e não reconhecimento social é produto da dialética da construção das normalidades e anormalidades espaciais. O conflito entre o permitido e o proibido, por um lado possibilita transformações sociais, por outro lado é atributo da construção hegemônica contraditória do espaço social, porque identifica os lugares, os sujeitos e as práticas transgressivas de deverão ser reprimidas.

As microterritorializações/microterritorialidades indevidas são frutos dos próprios processos sociais hegemônicos. Há um fetiche que produz a visibilidade espacial da diferença: por um lado as margens desejam a centralidade das relações sociais, por outro lado a centralidade precisa da margem para se constituir como poder. Em pesquisa na cidade de Presidente Prudente (SP), observamos claramente esta relação espacial em fetiche na localidade do Parque do Povo, no início da noite (pesquisa estabelecida em 2014). A rua que margeava o Parque, nas proximidades do shopping center, se tornou uma fronteira de visibilidade entre diferentes classes sociais. De um lado da rua ocorria a frequência de população de classe média consumidora em bares famosos da cidade, do outro lado da rua jovens adolescentes de periferia se reuniam nas margens do parque e da rua. Ambas as populações assistiam-se em uma relação de complementaridade de existência pela contradição entre separação e proximidade espacial. 


\section{b. Segundo subprincípio de forma: escala.}

A partir do que desenvolvemos até então, estamos nos referimos a um pequeno espaço apropriado sobrepondo uma configuração singular do espaço social: apropriação de uma configuração territorial produzida pelo mercado e/ou planejamento do Estado (como um shopping center e uma praça). A microterritorialização poderá ser uma parte apropriada ou poderá preencher toda a configuração do território primeiro (frequência de sujeitos LGBTs para sexo casual em um banheiro público, por exemplo). Em termos de escala, estamos falando de configurações de produções territoriais (em processo, sempre incompleto e transitório) em muito grande escala ou pequeno espaço de observação. No entanto, existem diferenças contrastantes nas microterritorializações que estão relacionadas às formas de relações estabelecidas entre os sujeitos (lembramos: o espaço são as relações sociais, conforme Massey (2009), um maior apinhamento e visibilidade ou uma circulação/ presença tênue/esperta/camuflada/quase invisível.

Existem microterritorializações que se constituem visivelmente por um 'apinhamento' forte e interações consistentes mais fechadas de um grupo de homens gays (Posto $9 \mathrm{em}$ Ipanema, Bar do Deca na Praia Mole em Florianópolis e proximidades do Monumento dos Expedicionários no Parque da Redenção em Porto Alegre nos domingos, por exemplo). Neste caso há uma forte microterritorialidade (espacialização de identidade) que objetiva a consolidação de um compartilhamento mais restrito de ações e apresentações (vide Bar do Deca na praia Mole, nas quais as formas de apresentação dos corpos, o tipo de música, os comportamentos e as interações sociais são muito parecidas e constroem uma forma homogênea às relações espaciais).

Ao contrário, há também certa retração da forma da microterritorialização em deixar o território primeiro (ou parte singular do espaço social) ser mais visível para que a presença ocorra na necessidade de práticas camufladas e sutis. Neste caso, teremos uma preponderância do aspecto de microterritorialidade, porque os sujeitos mais objetivam no espaço ações compostas nas intimidades individualizadas - existem os acasos dos encontros somente, não ocorrendo um forte processo de imitação e intensidade de reunião de corpos que tornam visível uma materialidade relacional -, do que constroem uma forma visível e uma demarcação coletiva. No entanto, a sutileza permite o trânsito e as oportunidades diversas sem construção de um cimento de identidade da microterritorialização. Nestas realidades ocorre uma identificação de parte do espaço nas quais determinados encontros casuais poderão acontecer, onde sujeitos transitam sozinhos e cujos contatos e formas de comunicação são muito sutis.

Podemos evidenciar isto no uso de banheiros públicos para sexo casual entre homens (COSTA, 2014), cuja imagem partilhada é um conhecimento disseminado por diferentes homens além da própria microterritorialização. Na presença no banheiro, há um conjunto de práticas corporais que estabelecem um jogo entre visibilidade e invisibilidades dos propósitos a serem estabelecidos, tornando-o pouco visível aos desinteressados.

Neste caso, existem sempre contradições referentes à identidade homossexual. Nas microterritorializações de forte apinhamento de corpos e visibilidade externa de práticas 
sociais há uma forte identidade homossexual que é compartilhada internamente (mesmo que alguns não se identifiquem como homossexuais, partilham da aceitação da visibilidade dos outros). Nas microterritorializações cuja invisibilidade e sutileza são regra, há sempre sujeitos que praticam sexo homossexual e não se identificam como homossexuais. Mesmo para aqueles que se identificam como homossexuais, a invisibilidade de sua identidade passa a ser regra, tornando-se sutilmente estabelecida. Muitos sujeitos que se identificam como homossexuais também procuram nestas microterritorializações outros sujeitos que, pelo contrário, não se identificam como homossexuais e não frequentam outras microterritorializações tidas como das homossexualidades para terem experiências sexuais. Existem possibilidades, assim, de ocorrem práticas sexuais homossexuais sem os sujeitos se identificarem como homossexuais (PARKER; TERTO JR, 1998) e espaços apropriados cujos estes encontros sexuais poderão acontecer.

\section{c. Primeiro subprincípio de conteúdo: a objetividade da troca e da imitação}

Para o pesquisador, há como observar, estando entre os sujeitos, quais os assuntos da moda, quais as expressões compartilhadas e imitadas, quais as formas mais admiradas de apresentação dos corpos. Existe uma necessidade, assim, de conviver, fazer amizades, exercer as práticas estabelecidas e conversar com um maior número de membros da microterritorialização. A presença na microterritorialização é necessária para entender as profundidades de microterritorialidade (identidade e subjetividades compartilhadas no espaço apropriado). Também existirão pequenos tabus, pequenas admirações e pequenas negações/marginalizações nas relações que colocam certos sujeitos em centralidade e outros em marginalidade na construção da sociabilidade em um apinhamento microterritorial.

Todo sujeito que se interessa em participar, aprende como se comportar e a melhor performance de corpo constrói a sua capacidade de ser admirado e de estar se relacionando com um conjunto de amigos e outros homens disponíveis ao sexo e a afetividade (nas microterritorialidades de homens gays, por exemplo). O pesquisador, então, deverá aprender a se constituir neste jogo relacional, assim como afastar-se dele para poder abstraí-lo para o pensamento descritivo: antes de tudo são práticas que não serão refletidas, mas reflexibilizadas (COULON, 1995). Caberá ao pesquisador trazer para a reflexão a reflexibilidade vivida por ele. Isto implica um longo tempo de convivência e um conjunto de crises sobre sua presença na convivência microterritorializada, que abalará os caminhos de sua pesquisa (pelas contradições e insuficiências percebidas) e os pensamentos sobre si mesmo.

\section{d. Segundo subprincípio de conteúdo: a subjetividade dos sujeitos da microterritorialidade}

Os sujeitos que participam de uma sociabilidade apresentam algo a dizer e pensam sobre seus posicionamentos localizados no tempo e no espaço: suas admirações, sua felicidade em serem reconhecidos e admirados por amigos e amantes, e de poderem objetivar 
intimidades que não poderiam ser visibilizadas em outros espaços sociais. Por outro lado, há também as insuficiências e negações em relação aos rituais, as formas de apresentação e as próprias incapacidades de serem admirados por outros, o que gera sofrimento. Há uma perspectiva fenomenológica que relaciona topofilias e topofobias (TUAN, 1980) de forma muito complexa para cada um em relação as construções de microterritorialidades. Não exatamente os sentimentos são dicotômicos, os sujeitos participam, agem em prol de um reconhecimento e se esforçam para se posicionarem da melhor forma em relação a uma coletividade microterritorializada, mas as situações diversas agem como atributos de atração e repulsão tornando isto um profundo problema subjetivo a convivência. Estas relações, com o passar do tempo, determina a seleção dos sujeitos e funcionam como 'fronteiras de convivência' (COSTA, 2002).

Há interesses e formas de entendimentos diversas sobre os processos de sociabilidade das microterritorialidades. Muitos sujeitos trazem para a convivência diferentes elementos de vivências em outros espaços (uma questão de relações de escalas também). Muitas vezes, o que reúne os sujeitos é um signo, como, por exemplo, o conhecimento de que em determinado lugar há determinada frequência de sujeitos LGBTs. Esta identidade compartilhada além da microterritorialização propriamente dita, a microterritorialidade, poderá ser uma falácia em determinado tempo de frequência de um determinado sujeito LGBT. Suas experiências poderão ser outras, embora isto não perturbe a construção de uma ideia geral sobre os fatos microterritorializados.

Estas relações produzem desacordos ao centro construído da microterritorialização ou, então, poderá trazer interesse pelo fetiche da diferença entre iguais. Os sujeitos mantêm diferentes experiências na localização das suas relações, embora o cimento que as constituam seja um princípio de igualdade aparente (apresentação dos corpos, pequenos rituais, materialidade do 'apinhamento', assuntos partilhados). Um exemplo clássico deste aspecto é a relação entre homens gays de classe alta e turistas que se reúnem no Posto $9 \mathrm{da}$ Praia de Ipanema e se interessam por outros homens de classes mais baixas da periferia carioca, que eventualmente estão na microterritorialização também atraídos pela forma homogênea que se concebe como sendo de homens brancos e turistas de classes mais altas. A suposta homogeneidade das relações, neste caso, acontece não por uma igualdade de estilos, mas por estas experiências entre sujeitos de condições sociais muito diferentes e tala diferença se constitui como um dos fundamentos principais da atração afetivo-sexual.

Em algumas casas noturnas do Rio de Janeiro isto também acontece, por outro lado, em outras casas as relações afetivo-sexuais se estabelecem somente entre corpos muito parecidos, como é o caso da conhecida convivência entre homens gays muito malhados de academia na casa noturna The Week. Existe uma pré-disposição de estranhamento em relação àqueles que não são malhados e um vínculo de afetividade vinculada sobre algumas apresentações de corpo. Como desafio a esta determinação das relações gays em muitas grandes cidades brasileiras, se desenvolveu uma comunidade de homens gays cujos corpos são mais gordos e peludos, denominados de 'ursos' ou bears. Em São Paulo festas específicas reúnem tais sujeitos construindo certa homogeneidade da reunião, como a casa noturna Ursound. Mesmo entre uma suposta homogeneidade, novas configurações 
identitárias se constroem em virtude de certas diferenças, principalmente em relação ao porte corporal, as idades e as formas estéticas apresentadas por homens gays ursos.

\section{CONSIDERAÇÕES FINAIS}

O objetivo deste trabalho foi discutir sobre os conceitos de microterritorialidades e microterritorializações, para contribuir com o debate estabelecido entre o grupo de pesquisadores das microterritorialidades nas cidades e 'múltiplas territorialidades', assim como para pesquisas que se interessam sobre a temática. Estes conceitos são caros à vida acadêmica do autor e suas pesquisas, assim o artigo dá ênfase aos fatos que levaram a assumir esta importância teórica. Os vínculos de pensamento são explicados mediante a estratégia metodológica de explicitar as condições de posicionalidade de quem escreve, no intuito de esclarecer sobre as origens dos argumentos aqui colocados. Esta estratégia se apresenta importante para melhor contextualizar os aportes empíricos, teóricos e pessoais na construção do pensamento, tornando honesta esta produção. Isto melhor capacita o leitor ao diálogo e a constituição de críticas, permitindo revisões futuras sobre supostos equívocos em uma constante revisão de fundamentos.

Sobre o propósito explicativo principal, organizamos o discurso em relação a dois outros conceitos: o de forma e de conteúdo. Em relação à forma coincidimos o conceito de microterritorialização. Em relação ao conteúdo aproximamos o conceito de microterritorialidade. O jogo teórico apresenta-se como um esquema didático que serve para dar ênfase a constatações singulares que nunca poderão ser operacionalizadas em separado. Por um lado existem formas (aparências) das pequenas apropriações de corpos em partes do espaço urbano, por outro lado os conteúdos explicativos das aparências estão relacionados às questões de sociabilidade (objetividade das práticas culturais), de identidade (compartilhamentos intersubjetivos) e de intimidade (subjetividades de cada presente).

Procurando aprofundar ainda mais as análises, construímos subprincípios aos princípios de forma e de conteúdo. Os subprincípios analisam as questões referentes à escala e a apropriação de um espaço construído em primeira instância (estes dois referentes aos subprincípios de forma), assim como os atributos compartilhados entre sujeitos em sociabilidade microterritorializada (pequenos rituais, pequenos mitos e processos de imitação na construção de identidade) e as divergências contidas nas intimidades e subjetividades de cada um (estas duas últimas características são referentes aos subprincípios de conteúdo).

Como já argumentamos, propusemos tornar complexas e esclarecer elementos diversos contidos nos conceitos de microterritorialização e microterritorialidade, para serem mais bem operacionalizados em outras pesquisas. Esperamos maiores contribuições críticas a partir deste texto, para tornar mais cabíveis estas possibilidades teóricas e metodológicas. Os eventos que discutem estas questões já se encaminham para uma quinta edição e são repletos de possibilidades de articulações sobre outras análises empíricas. Pensamos que existe uma necessidade de uma melhor construção epistêmica sobre tais conceitos e suas capacidades de servirem como teorias explicativas de realidades diversas. 


\section{REFERÊNCIAS}

BUTLER, Judith. Problemas de gênero: feminismo e subversão da identidade. Rio de Janeiro: Civilização Brasileira, 2010.

CLAVAL, Pierre. O papel da nova geografia cultural na compreensão humana. In: ROSENDAHL, Zeny; CORREA, Roberto L. (Orgs.) Matrizes da Geografia Cultural. Rio de Janeiro: EdUERJ, 2001.

COSTA, Benhur P. da. A condição homossexual e a emergência de territorializações. 2002. Dissertação (Mestrado em Geografia) - Universidade Federal do Rio Grande do Sul, Porto Alegre - RS.

. Práticas espaciais de "pegação" homoerótica: o caso dos banheiro públicos nas cidades de Presidente Prudente (SP) e Vitória da Conquista (BA). Revista Latino-Americana de Geografia e Gênero, v. 5, n. 1, p. 152-179, 2014.

.; CRUZ, Jasson Iran Monteiro da; FRANÇA, Josevaldo Sousa de. Oposições e complementaridades nas práticas homoafetivas de microterritorialização: interações entre "bichas" e "bofes" na Praia do Osso em Santarém-PA In: SILVA, Maria das G.S. da; SILVA, Joseli M. Interseccionalidades, Gênero e Sexualidades na análise espacial. Ponta Grossa: Todapalavra, 2014.

COULON, Alain. Etnometodologia. Petrópolis: Vozes, 1995.

FOUCAULT, Michel. História da sexualidade: a vontade de saber. Rio de Janeiro: Graal, 1988. v. 1.

GOFFMAN, Erving. A Representação do eu na vida cotidiana. Petrópolis: Vozes, 1996.

GOMES, Paulo C. da C. A condição urbana: ensaios de geopolítica da cidade. Rio de Janeiro: Bertrand Brasil, 2002.

JAMESON, Fredric. O pós-modernismo: e a lógica cultural do capitalismo avançado. São Paulo: Ática, 1991.

KNOPP, Larry. On the relationship between queer and feminist geographies. The Professional Geographer, v. 59, n. 1, p. 47-55, 2007.

MAFFESOLI, Michel. O tempo das tribos: o declínio do individualismo nas sociedades de massa. Rio de Janeiro: Forense Universitária, 2002.

MASSEY, Doreen. Pelo espaço: uma nova política da espacialidade. Rio de Janeiro: Bertrand Brasil, 2009.

MATURANA, Humberto R. Tudo é dito por um observador. In: MAGRO, Cristina; GRACIANO, Miriam; VAZ, Nelson. Humberto Maturana: A ontologia da realidade. Belo Horizonte: UFMG, 1997.

PARKER, Richard; TERTO JUNIOR, Veriano de Souza (Orgs.). Entre homens: homossexualidade e AIDS no Brasil. São Paulo: ABIA, 1998.

PARKER, Richard. Abaixo do Equador: culturas do desejo, homossexualidade masculina e comunidade gay no Brasil. São Paulo: Record, 2002.

PEDROSO, Luciano F. O espaço cotidiano dos agregados sociais da praça da alfândega em Porto AlegreRS. 2007. Dissertação (Mestrado em Geografia) - Universidade Federal do Rio Grande do Sul, Porto Alegre - RS.

RAFFESTIN, Claude. Por uma geografia do poder. São Paulo: Ática, 1993.

ROSE, Gillian. Feminism and Geography: the limits of Geographical Knowledge. Cambrige: Polity Press, 1993.

Situating knowledges: positionality, reflexities and other tactics. Progress Human Geography, v. 21, n. 3, p. 305-320, 1997.

SANTOS, Milton. A natureza do espaço. Técnica e tempo. Razão e Emoção. São Paulo: HUCITEC, 1996.

SEDGWICK, Eve K. A epistemologia do armário. Cadernos Pagu, n. 28, p. 19-54, jan./jun. 2007.

SILVA, Armando. Imaginários urbanos. São Paulo: Perspectiva, 2001. 
SILVA, Alexandro. Processos de territorialização em espaços marginais: estudo exploratório e descritivo das vivências de homens que fazem sexo com outros homens na cidade de Praia Grande/SP. 2013. Dissertação (Mestrado em Ciências da Saúde) - Universidade Federal de São Paulo, Santos - SP.

SILVA, Joseli M. Geografias feministas, sexualidades e corporalidades: desafios às práticas investigativas da ciência geográfica. In: ___ Geografias subversivas: discursos sobre espaço, gênero e sexualidades. Ponta Grossa: TodaPalavra, 2009.

; ORNAT, Marcio J. Interseccionalidade e mobilidade transnacional entre Brasil e Espanha nas redes de prostituição. Revista Anpege, v. 8, n. 10, p. 51-66, 2012.

TEDESCO, João C. Paradigmas do cotidiano: introdução à constituição de um campo de análise social. Passo Fundo: EDUNISC/ UPF, 2003.

TOURAINE, Alain. Crítica da modernidade. Petrópolis: Vozes, 1994.

TUAN, Yi-Fu. Topofilia: um estudo da percepção, atitudes e valores do meio ambiente. São Paulo: Difel, 1980. 